\title{
Prioritization of predisposing factors of gingival hyperplasia during orthodontic treatment: the role of amount of biofilm
}

Séverine Vincent-Bugnas ${ }^{1,2,3^{*}} \mathbb{C}$, Leslie Borsa ${ }^{2,3,4}$, Apolline Gruss ${ }^{2,5}$ and Laurence Lupi ${ }^{2,3,4}$

\begin{abstract}
Background: The mechanism of gingival growth that may occur during fixed orthodontic treatment is not yet fully understood and the amount of dental plaque is often incriminated. The objective of this study was to evaluate the prevalence of gingival growth during multi-attachment orthodontic treatment and to prioritize its predicting factors, especially the quantity of biofilm.

Methods: This comprehensive cross-sectional descriptive study was conducted on orthodontic patients aged 9 to 30 years, in good health, treated by a fixed appliance. Periodontal clinical parameters such as plaque index, gingival index, probing pocket depth, periodontal phenotype and gingival enhancement index were recorded. Likewise, the brushing habits and the date of the last scaling were noted. The orthodontic parameters studied were the duration of the treatment, the type of bracket, the alloys used for the arches and the type of ligatures. Descriptive statistics were carried out, and variables presenting $p$ value $<0.25$ were included in a multivariate analysis to calculate the Odds Ratio (OR) of gingival enlargement".
\end{abstract}

Results: A total of 193 patients were included (16.38 44.89 years). Gingival growth occurred for $49.7 \%$ of patients included. The predisposing factors for this pathology during fixed orthodontic treatment were conventional metal brackets $(p=0.021)$, mouth breathing $(p=0.040)$, male gender $(p=0.035)$, thick periodontal phenotype $(p=0.043)$, elastomeric ligations $(p=0.007)$, duration of treatment $(p=0.022)$ and presence of plaque $(p=0.004)$. After achievement of the logistic regression, only two factors remained related to gingival enlargement: metallic brackets (OR: $3.5,95 \% \mathrm{Cl}: 1.1-10.55)$ and duration of treatment (OR: $2.03,95 \% \mathrm{Cl}: 1.01-4.08)$. The amount of plaque would not be directly related to the development of gingival increase during orthodontic treatment.

Conclusions: Among the predisposing factors that underlie gingival growth during multi-attachment therapy, the amount of plaque is not found. The qualitative assessment of the plaque and its evolution during treatment could clarify the role of the biofilm in the occurrence of gingival overgrowth.

Keywords: Gingival overgrowth, Orthodontic treatment, Risk factors, Dental plaque

*Correspondence: Severine.VINCENT@univ-cotedazur.fr

1 Département de parodontologie, Université Côte d'Azur, UFR

Odontologie, 24 Avenue des diables bleus, 06300 Nice, France

Full list of author information is available at the end of the article

\begin{abstract}
Background
The effect of fixed orthodontic appliances on periodontal health has already been demonstrated [1-7]. Obviously, by hindering access to good oral hygiene and creating microbial shelters (both resulting in the accumulation of plaque), bonded orthodontic brackets impede good oral hygiene, resulting in a threat for periodontal health [7]. Among the periodontal diseases that occur during fixed
\end{abstract}


orthodontic treatment, we find mainly orthodontic gingivitis or more precisely "gingivitis induced by bacterial biofilms and modified by local risk factors" in the new EFP classification [8], gingival recessions (or "peri-dental muco-gingival abnormalities") and gingival growth [9]. Gingival enlargement (GE) is excessive growth of the gums where the inflammatory tissue may be in a limited region, or it may be generalized [1-4]. The three parts of gingival mucosa can be reached (marginal gingiva, interdental papilla and attached gingiva). It is most often due to an increase in the extracellular matrix of the mucosal chorion (collagen and fundamental substance with glycosaminoglycans such as hyaluronic acid, heparan sulfate or chondroitin sulfate, elastin, laminin or fibronectin) and more rarely bound to the epithelium.

The exact mechanism of this increase is not yet fully elucidated [9-11]; it is not necessarily associated with an increase in the number or size of fibroblasts. It is more likely a gingival enlargement or gingival increase "gingival overgrowth or gingival enlargement" than a strictly hypertrophy or gingival hyperplasia. Increased expression of type I collagen mRNA and regulation of growth of keratinocyte growth factor receptors may play an important role in excessive proliferation of epithelial cells and development of gingival growth [12].

The placement of orthodontic brackets leads to adverse changes in the composition of the bacterial plaque, both quantitatively and qualitatively, increasing both the periodontal risk and the carious risk. Indeed, an increase in spirochetes, periodontal pathogens such as Prevotella Intermedia, Aggregatibacter actinomycetemcomittans, Porphyromonas gingivalis or Fusobacterium Nucleatum [13] (as well as in Candida sp. [14]) is reported, and the presence of orthodontic brackets obviously makes the maintenance of good oral hygiene, particularly in interproximal spaces, much more difficult [15]. Finally, orthodontic treatments are often initialized during adolescence, that means when compliance and adherence to oral hygiene are quite difficult to obtain [16].

The accumulation of supra-gingival plaque then induces inflammatory alterations of the gingival tissues. However, the responses to this aggression both in their clinical form and in their time of appearance greatly vary with the individual [17]. These responses may depend on the quality and / or quantity of the biofilm and the host's immune response to this aggression [18].

While some studies clearly indicate poor hygiene as responsible for gingival growth $[19,20]$, others demonstrate that gingival changes during orthodontic treatment are transient and do not imply any permanent alteration of periodontal tissue $[4,5,21]$. Although, these lesions, creating artificially deep periodontal pockets, must not be neglected and require treatment. Moreover, anterior
GE promotes a negative impact on oral health-related quality of life of orthodontic patients [22].

To our knowledge, few studies have yet studied the predisposing factors associated with gingival growth during orthodontic treatment $[1,2]$. The aim of this study was therefore to evaluate the prevalence of gingival growth during fixed orthodontic treatment and the factors related to it, using a hierarchical approach with a particular focus on the role of the amount of biofilm in its development.

\section{Methods \\ Study population}

All patients undergoing fixed orthodontic treatment were selected from patients treated in the dentofacial orthopedics department in the Nice University Hospital. The research council of the dental faculty of Nice University validated the study and the Delegation for Clinical Research and Innovation of University Hospital of Nice agreed to carry out this study. An informed written participant consent was obtained for each participant. For the minors included in the patient sample the consent to participate was obtained from a parent or guardian on behalf of the participants.

The study was a comprehensive cross-sectional survey: all patients, aged less than 30 years and treated with fixed attachments between october and november 2016 were eligible. Informed consent explaining the objectives of the study was signed and kept in the patients' files.

Fixed corrective orthodontic treatment was carried out with conventional metal brackets, self-ligaturing brackets or ceramic brackets, straight wire technique, orthodontic arches fixed with simple elastomeric ligatures, metal ligatures, but without elastic chains, or proximal enamel stripping. Orthodontic rings (bands) were adapted to the molars with glass ionomer cement.

Patients suffering from congenital abnormality, systemic illness, cysts, or crevices, or with special needs or using systemic medication for the treatment of chronic diseases that might interfere with gingival overgrowth were excluded from the sample. Patients who required chemoprophylaxis before clinical examination were also excluded, as well as pregnant women and smokers.

The required number of subjects was estimated based on an expected difference of $10 \%$ with a theoretical proportion of $30 \%$ of GE [1]. Considering a power of $80 \%$ and a confidence interval of $95 \%$, at least 172 persons were required.

We chose a face-to-face data collection, which provides a more accurate screening, with the operator's (A.G) help.

Clinical examinations of all the patients were carried out by the same clinical operator (A.G.) previously 
calibrated by the members of the periodontal department. Training sessions were performed to ensure examiner reliability in regard to all the indices (Plaque Index, Gingival index, probing pocket depth and Seymour gingival growth index) [23] before the study started. Assessment of measurement reproducibility were conducted, for the Seymour gingival growth index only (other indices represent too variable conditions [1]), with 15 subjects. Replicate measurements were made by the examiner with a 2-day interval. An unweighted kappa value of 0.85 was obtained.

\section{Survey}

A questionnaire was completed by the investigator for each patient. The survey developed for this study is provided as Additional file 1 . The different items were collected and then checked using the patient's file. Data entry was anonymous, and no information in the electronic file could be used to identify the source person. The form was structured in 3 parts:

- A first paragraph containing general data: The patients were interviewed using standardized modalities and a questionnaire with closed questions about sociodemographic data that included the following: age, gender, ethnicity, father's or mother's profession or patient's own profession if appropriate, using the INSEE (French Institute for statistics and economic studies) Scale and then, for statistical purposes, grouped into 3 classes (management profession, employees, or without employment), medical status and drug treatments,

- The second paragraph dealt with periodontal health: the presence of overgrowth and, if any, the severity and localization were noted: The extent of gingival increment was classified as localized $(<4$ papillae involved) or generalized ( $>4$ papillae involved) [24]. For the anterior segment, the degree of gingival thickening on both labial and lingual side of each five papillae was graded as follows: $0=$ no increase, $1=$ increase $\leq 2 \mathrm{~mm}, 2=$ increase $>2 \mathrm{~mm}$ and the gingival encroachment was graded as: $0=$ normal, $1=$ papilla involving $1 / 3$ of adjacent tooth crown half, $2=$ papilla involving $2 / 3$ of adjacent tooth crown half, $3=$ papilla involving $>2 / 3$ of adjacent tooth crown half. These two scores were added, thus giving the Seymour gingival growth index [23]. The proportion of subjects with a Seymour index value of 30 or greater based on the cutoff proposed by the index for the definition of clinically relevant GE $[1,23]$.

Evaluation of the quality of oral hygiene by Silness and Loë's plaque index (PI) (0: absence of plaque; 1: plaque not visible to the naked eye but detachable with the probe, 2: plaque visible to the naked eye, 3: abundant plaque visible to the naked eye in the sulcus and on the marginal gingiva [25], gingival inflammation by the gingival index (GI) of Loë and Silness (0: absence of inflammation, 1: mild inflammation, 2: moderate inflammation and induced bleeding, 3: severe inflammation, spontaneous bleeding) [26] and gingival phenotype (thin: periodontal probe visible through the marginal gingiva, or thick: probe not visible by transparency) [27], the brushing habits (frequency, hygiene equipment), the date of the last periodontal scaling were also noted.

Breathing (nose or mouth breathing) is systematically collected in the patients' file. It was assessed thanks to both visual assessment and two tests: lip seal test for 3 minutes and Glaze test (mirror's test) [28].

The last paragraph concerned orthodontic data: treatment duration, type of brackets, alloys used for orthodontic arches, type of ligatures. All this information is systematically collected in the file and was just double checked by the examiner (A.G).

\section{Statistical analysis}

The statistical data was collected in a spreadsheet and analyzed using IBM SPSS software version 25.0 (Statistical Package for Social Services, Chicago, IL, USA). Descriptive statistics were performed with flat sorting: frequencies for the qualitative variables. The influence of different variables on the presence of a gingival growth was studied. Some variables were "binarized" when the numbers were too small. The plaque index and the gingival index were dichotomized in a "yes/no visible plaque" and in a "yes/no gingival bleeding". Age and duration of treatment, were changed into ordinary scales and treated as categorical variable in logistic regression analysis.

The enlargement was considered "present" if it concerned at least 4 papillae [24]. It was analyzed with Chisquare test for qualitative variables. The significance threshold was set at $<0.05$. Potentially significant variables $(p<0.25)$ in univariate analyses were then entered into a multivariate logistic regression model and variables that remained significant were ordered to hierarchize associated factors. The forward stepwise likelihood ratio method for analyses was used, as well as the fitness index (Hosmer-Lemeshow test).

\section{Results \\ Description of the sample}

A total of 193 patients were included in the study. They were divided into 68 boys and 125 girls. The Caucasians were the most numerous (more than half) while the Maghrebians (or North Africans) accounted for about 
Table 1 General characteristics of studied population

\begin{tabular}{llr}
\hline & Characteristics & $\%$ \\
\hline Sex & Boys & 35.2 \\
& Girls & 64.8 \\
Age groups & $9-13$ years & 7.3 \\
& $13-19$ years & 49.2 \\
Ethnicity & 20 years and more & 43.5 \\
& Caucasian & 53.9 \\
& From Maghreb & 32.6 \\
& From Africa & 12.4 \\
General health problems & From Asia & 1.0 \\
& None & 86.5 \\
& Related to oral sphere & 6.2 \\
& Not related to oral sphere & 7.3 \\
\hline
\end{tabular}

one third of our sample. All the patients were in good physical condition (Table 1).

\section{Periodontal parameters}

Considering that at least 4 papillae should be involved, gingival enlargements concerned nearly half of the patients treated with fixed attachments (49.7\%) and boys were more affected $(60.3 \%)$ than girls $(44 \%)(p=0.035)$. These gingival complications did not depend on ethnicity. No relationship could be found with general health $(p=0.41)$, whereas impaired ventilation had a significant impact on gum health: more than half of mouth breathers (53.6\%) had gingival enlargement while only one-third (35\%) of those who normally breathed, through the nose $(p=0.05)$ were concerned. The gingival phenotype was also found to be a predisposing factor for gingival growth since it was much more frequent when the periodontium was thick $(61 \%)(p=0.043)$.

Univariate analyses showed that the presence of bacterial plaque seems to have played a determining role in the occurrence of gingival hyperplasia since its prevalence increases gradually from $20 \%$ in the absence of plaque $(\mathrm{IP}=0)$ to $72 \%$ in case of abundant plaque $(\mathrm{IP}=3)$, passing through $46 \%$ if the plaque was detectable only after scraping with the probe $(\mathrm{IP}=1)$ and $55 \%$ if it was visible to the naked eye $(\mathrm{IP}=2)(p=0.004)$. These results are different from those found by multivariate analysis which does not reveal the amount of dental plaque as predisposing factor in enlargement overgrowth.

However, brushing frequency did not appear to be statistically related to gingival enlargement $(p=0.89)$. As all the patients didn't present periodontitis, the increase of periodontal probing highlights the presence of false pockets characteristic of gingival overgrowth related to orthodontic mechanics.

\section{Orthodontic parameters}

Gingival overgrowth was more common with metal brackets (53\%) than with ceramic brackets (26\%) $(p=0.021)$. The presence of nickel in the arch did not influence their appearance $(p=0.18)$. On the other hand, elastomeric ligations appear to have clearly favored them (58\%) compared to metal ones or selfligating brackets $(38.9 \%)(p=0.007)$ (Tables 2,3$)$. Significant variables (sex, kind of ventilation, amount of plaque, gingival phenotype, type of ligations, type of brackets) in univariate analyzes, were therefore included in a logistic regression model. Thus, it became possible to hierarchize the predisposing factors for gingival overgrowth during orthodontic treatment with fixed appliance: conventional metal brackets increased the risk for GE by 3.5 (95\% CI: 1.1-10.55) and the duration of treatment also increased the risk for GE by 2.02 (95\% CI: 1.01-4.08). Significant predisposing factors in univariate analyses (gender, breathing, periodontal phenotype, plaque and ligations) became not significant in the logistic regression (Table 4).

Table 2 Orthodontic characteristics of studied population

\begin{tabular}{|c|c|c|}
\hline & Characteristics & $\%$ \\
\hline \multicolumn{3}{|l|}{ Exclusive mouth breather } \\
\hline No & 153 & 79.3 \\
\hline Yes & 40 & 20.7 \\
\hline \multicolumn{3}{|l|}{ Oral Hygiène (OHI) Plaque index } \\
\hline $\mathrm{IP}=0:$ No plaque & 24 & 12.4 \\
\hline $\begin{array}{l}\mathrm{IP}=1 \text { Plaque visible after scratching at the } \\
\text { probe }\end{array}$ & 67 & 34.7 \\
\hline $\mathrm{IP}=2$ Plaque visible with naked eye & 84 & 43.5 \\
\hline $\mathrm{IP}=3$ Abondance of plaque & 18.0 & 9.3 \\
\hline \multicolumn{3}{|l|}{ Frequency of brushing } \\
\hline At least twice a day & 176 & 91.2 \\
\hline Once a day or less & 17 & 8.8 \\
\hline \multicolumn{3}{|l|}{ Gingival phenotype } \\
\hline Thick & 59 & 30.6 \\
\hline Thin & 134 & 69.4 \\
\hline \multicolumn{3}{|l|}{ Type of orthodontic brackets } \\
\hline Metal & 170 & 88.1 \\
\hline Ceramic & 6 & 3.1 \\
\hline Maxillary ceramic and metal in the mandible & 17 & 8.8 \\
\hline \multicolumn{3}{|l|}{ Orthodontic arch type } \\
\hline Containing nickel & 60 & 31.1 \\
\hline Steel & 133 & 68.9 \\
\hline \multicolumn{3}{|l|}{ Ligatures } \\
\hline Metal & 7 & 3.6 \\
\hline Elastomerics & 109 & 56.5 \\
\hline Both & 72 & 37.3 \\
\hline Self-ligating & 5 & 2.6 \\
\hline
\end{tabular}


Table 3 Bivariate and gingival status

\begin{tabular}{|c|c|c|c|}
\hline \multirow[t]{2}{*}{ Variables } & \multicolumn{2}{|c|}{$\begin{array}{l}\text { Presence of gingival } \\
\text { overgrowth (n) }\end{array}$} & \multirow[t]{2}{*}{$p$} \\
\hline & Yes & No & \\
\hline \multicolumn{4}{|l|}{ Sex } \\
\hline Girls & 55 & 70 & 0.035 \\
\hline Boys & 41 & 27 & \\
\hline \multicolumn{4}{|l|}{ Age } \\
\hline $9-13$ & 11 & 3 & 0.18 \\
\hline $13-19$ & 56 & 39 & \\
\hline$>20$ & 29 & 55 & \\
\hline \multicolumn{4}{|l|}{ Ethnicity } \\
\hline Caucasian & 50 & 54 & 0.56 \\
\hline Maghreb & 34 & 29 & \\
\hline African & 12 & 12 & \\
\hline Asian people & 0 & 2 & \\
\hline \multicolumn{4}{|l|}{ General health problem } \\
\hline None & 81 & 86 & 0.41 \\
\hline Not related to oral health & 8 & 4 & \\
\hline Related to oral health & 8 & 6 & \\
\hline \multicolumn{4}{|l|}{ Mouth breathing } \\
\hline Yes & 82 & 71 & 0.04 \\
\hline No & 14 & 26 & \\
\hline \multicolumn{4}{|l|}{ Presence of plaque } \\
\hline None & 5 & 19 & 0.004 \\
\hline Little & 31 & 36 & \\
\hline Visible & 47 & 37 & \\
\hline Large amount & 13 & 5 & \\
\hline \multicolumn{4}{|l|}{ Frequence of brushing } \\
\hline At least twice a day & 87 & 89 & 0.89 \\
\hline Once a day or less & 9 & 8 & \\
\hline \multicolumn{4}{|l|}{ Periodontal phenotype } \\
\hline Thick & 36 & 23 & 0.043 \\
\hline Thin & 60 & 74 & \\
\hline \multicolumn{4}{|l|}{ Type of bracket } \\
\hline Metal & 90 & 80 & 0.021 \\
\hline Ceramic & 6 & 17 & \\
\hline \multicolumn{4}{|l|}{ Orthodontic arch } \\
\hline With nickel & 26 & 35 & 0.18 \\
\hline Without nickel & 70 & 62 & \\
\hline \multicolumn{4}{|l|}{ Type of ligature } \\
\hline Elastomerics & 63 & 45 & 0.0071 \\
\hline Metal or self-ligating & 33 & 52 & \\
\hline \multicolumn{4}{|l|}{ Duration of treatment } \\
\hline Less than 1 year & 53 & 42 & 0.022 \\
\hline Between 1 and 2 years & 47 & 20 & \\
\hline More than 2 years & 25 & 6 & \\
\hline
\end{tabular}

Table 4 Final multivariate logistic regression model of occurrence of gingival enlargement

\begin{tabular}{lll}
\hline & OR adjusted & $\begin{array}{l}\mathbf{9 5 \%} \text { confidence } \\
\text { intervals }\end{array}$ \\
\hline Duration of treatment & 0: less than 1 year & $2.03[1.01-4.08]^{*}$ \\
& 1: $1-2$ years & \\
2: more than 2 years & \\
Type of bracket & 0: ceramic & $3.5[1.1-10.55]^{*}$ \\
1: metal & \\
\hline
\end{tabular}

OR odds ratio

\section{Discussion}

In our study, considering that at least 4 papillae should be involved, according to the definition of "localized" form as described by Sibaud et al. [24], about half of the patients exhibited gingival overgrowth. Our study allows to hierarchize the predisposing factors for this side effect of fixed orthodontic treatment. Both the duration of treatment and the nature of the materials constituting orthodontic appliances appeared as predisposing factors. On the other hand, plaque, in its quantitative aspect (Plaque Index), does not appear directly related to the development of gingival growth.

Orthodontists tend to view the teenage period as very supportive of orthodontic treatment since usually all or most of the permanent teeth have erupted, while craniofacial growth can still be stimulated. This allows the teeth to be displaced and malocclusions corrected while maintaining favorable facial growth [29]. Thus, the majority of orthodontic treatments are undertaken during this period. However, in spite of the oral hygiene instructions systematically given at the beginning of treatment, young patients often have difficulties in maintaining a correct level of oral hygiene, especially during adolescence, where compliance is difficult to obtain [16] and hormonal changes may potentiate gingival inflammation [30]. However, in our study, while we would have expected to find more gingival overgrowth in girls for whom the hormonal impregnation is higher, boys were twice as often affected $(p=0.035)$. Androgenic factors may therefore be found histologically. Anyway, in the multivariate analysis, gender no longer appears to be a predisposing factor.

Inevitably, placement of a fixed orthodontic appliance creates plaque retention areas that make cleaning difficult [31]. However, the constant presence of bacterial plaque is inevitably accompanied by numerous side effects such as gingivitis, gingival overgrowth, demineralization of enamel (leading to precarious leucomas and even to caries) and, possibly in extreme cases, attachment loss [32, 33]. 
Adhesion of microorganisms to surfaces is a result of electrostatic interactions and Van-der-Walls forces [34]. Although it is clear that initial attachment is an important factor governing colonization, the principle of adhesion and subsequent growth of the biofilm may differ significantly [35]. Once initial adhesion is obtained, other factors may influence further colonization. Reduced wettability can inhibit direct adhesion and thus plaque formation on orthodontic devices [36]. Thus, the nature and the surface characteristics of both orthodontic brackets and composite may influence the retention of the biofilm. The method of ligation of the archwire is an additional factor of importance for plaque retention. Some studies have investigated the effects of fixed orthodontic appliances on the microbial flora profile, and, among them, few have compared the effects of bracket architecturespecifically. Metallic orthodontic brackets have already been found to induce specific changes in the buccal environment such as decreased $\mathrm{pH}$, increased accumulation and elevated S. mutans colonization [37, 38].

Besides, the archwire ligation method-induces a quantitative evaluation of the bacterial accumulation that occurs with the bonding of fixed appliances [7, 39-41]. In our study, the most common method of arch-wire ligation, elastomeric ties, was chosen as the basis of comparison against the SL mechanism and steel ligatures. They confirmed the propension for elastomeric ligations to retain plaque. However, this predisposing factor disappeared in the logistic regression.

In the same way, periodontal health is known to be a crucial element to consider before starting orthodontic treatment. If orthodontists are very much used to being cautious in case of proven periodontal disease or reduced periodontium after healing of a past pathology, the gingival phenotype must also be taken into consideration. The importance of the amount of keratinized tissue to maintain periodontal health has long been debated. Some have shown that the presence of keratinized tissue was not essential for periodontal health in the absence of plaque [42], or that the periodontitis could remain healthy even in the case of low height (at least $2 \mathrm{~mm}$ ) and attached gingiva thickness combined with control of plaque control [43]. However, these reduced narrow and thin gingival conditions represent well and truly a risk factor for the development of gingival recessions, especially if they are associated with a short vestibule, trauma or poor hygiene. Recently, studies with a long-term clinical follow-up (between 18 and 35 years) have shown that the transformation into a thick gingival phenotype by an epithelio-conjunctive graft favors the health of periodontal tissues [44]. A thick periodontium, in response to bacterial aggression, will tend to thicken and form periodontal pockets.
Thus, in our study, hyperplasia was much more common in the case of thick periodontium $(61 \%)$ than in the case of thin periodontium (44.8\%) $(p=0.043)$, but once again this predisposing factor disappeared in the logistic regression.

In our study, although the amount of plaque seemed to have played a determining role in the occurrence of gingival overgrowth in univariate analyses, since its prevalence increased gradually following a real gradient $(p=0.004)$, the role of the dental plaque quantity, after completion of the logistic regression, as apprehended by the index of Silness and Löe, seems to fade in favor of the other predisposing factors. This interpretation is confirmed by the fact that the frequency of brushing did not appear to be statistically related to gingival enlargement $(p=0.89)$. The explanation could lie in the qualitative and non-quantitative evolution of the dental plaque during fixed orthodontic treatment. This could lead to the qualitative selection of pathogens and the interindividual differences that might explain the different patterns of response and time needed for evident clinical responses, as well as local and systemic individual resistance or even a specific microbial challenge [17, $21,45]$. This finding seems to be supported by several microbiological studies which demonstrate that when fixed orthodontic appliances are placed, the potential for qualitative $[46,47]$ changes in the microbial composition of these areas enhances. Thus, periodontal reaction might be elicited by a change in the composition of the microbiological environment [21], even if the amount of plaque is not significantly involved.

So, gingival overgrowth was more frequent with metal brackets (53\%) than with the ceramic ones (26\%) $(p=0.021)$, the presence of nickel in the arches did not influence their appearance $(p=0.18)$, and elastomeric ligatures appear to have clearly favored them (58\%) compared with metal ligatures or self-ligating brackets $(38.9 \%)(p=0.007)$ (Tables 2, 3).

The strengths of our study lie in supplying data on a commonly met condition during fixed orthodontic treatment (gingival enlargement). The originality comes from the ranking of predisposing factors.

The limitations of our study arise from the crosssectional design, which only provides a snapshot of our outcome at a specific point in time and provides no indication of the sequence of events. Besides, we chose to study specific conditions that could appear to be potential predisposing factors for GE, but we might have omitted other ones that could have been of interest.

This study could contribute to improve clinical practice since awareness of related factors can guide the choice of practitioners or help them to advise their patients. 


\section{Conclusions}

Our initial hypothesis, namely the impact of the amount of biofilm in the occurrence of GE has not been verified. After completion of the logistic regression, the quantity of plaque would not be directly related to the development of this gingival increase. On the contrary, two conditions appeared to be real predisposing factors: the constituent material of the bracket and the duration of treatment. Thus, these results raise a new hypothesis: the quality of biofilm, instead of the amount of plaque, could be at the origin of the development of GE during orthodontic treatment. Therefore, studies on the qualitative evolution of plaque during fixed orthodontic treatment are needed to clarify the role of biofilm in the occurrence of gingival overgrowth.

\section{Supplementary Information}

The online version contains supplementary material available at https://doi. org/10.1186/s12903-021-01433-2.

Additional file 1. Use of data for research purposes.

\section{Abbreviations}

GE: Gingival enlargement; Gl: Gingival index; OR: Odds ratio; PI: Plaque index; PPD: Pocket probing depth.

\section{Acknowledgements}

We would like to thank all the patients, residents and practitioners of the functional unit of orthodontics and Dentofacial Orthopedics in Nice University Hospital for helping us carry out this study.

\section{Authors' contributions}

SVB contributed to the writing of the manuscript. LB contributed to the writing of the manuscript. AG has collected clinical data on patients. LL did the statistical analysis, the interpretation of the results. All authors read and approved the final manuscript.

\section{Funding}

The authors state that they have received no funding.

\section{Availability of data and materials}

The datasets used and/or analyzed during the current study are available from the corresponding author on reasonable request.

\section{Ethics approval and consent to participate}

The research commission of the UFR of odontology of Nice University validated the study and the Delegation for Clinical Research and Innovation of University Hospital of Nice agreed to carry out this study. This study was registred, according to the Data protection act (loi informatique et liberté) (\# 409). An informed written participant consent was obtained for each participant. For the minors included in the patient sample the consent to participate was obtained from a parent or guardian on behalf of the participants (Additional file 1).

\section{Consent for publication}

Not applicable.

\section{Competing interests}

The authors declare that they have no competing interests.

\section{Author details}

${ }^{1}$ Département de parodontologie, Université Côte d'Azur, UFR Odontologie, 24 Avenue des diables bleus, 06300 Nice, France. ${ }^{2}$ Pôle d'Odontologie, Centre
Hospitalier Universitaire de Nice, 5 Rue Pierre Dévoluy, 06000 Nice, France. ${ }^{3}$ Laboratoire MICORALIS EA7534, Université Côte d'Azur, 24 Avenue des diables bleus, 06300 Nice, France. ${ }^{4}$ Département de santé publique, Université Côte d'Azur, UFR Odontologie, 24 Avenue des diables bleus, 06300 Nice, France. ${ }^{5}$ Université Côte d'Azur, UFR Odontologie, 24 Avenue des diables bleus, 06300 Nice, France.

Received: 25 August 2019 Accepted: 9 February 2021

Published online: 24 February 2021

\section{References}

1. Pinto AS, Alves LS, do Zenkner JE, Zanatta A, Maltz FB. Gingival enlargement in orthodontic patients: effect of treatment duration. Am J Orthod Dentofac Orthop. 2017;152:477-82. https://doi.org/10.1016/j.ajodo .2016.10.042.

2. Zanatta FB, Moreira CHC, Rösing CK. Association between dental floss use and gingival conditions in orthodontic patients. Am J Orthod Dentofac Orthop. 2011;140:812-21. https://doi.org/10.1016/j.ajodo.2011.06.028.

3. Ellis PE, Benson PE. Potential hazards of orthodontic treatment-what your patient should know. Dent Update. 2002;29:492-6. https://doi. org/10.12968/denu.2002.29.10.492.

4. Gomes SC, Varela CC, da Veiga SL, Rösing CK, Oppermann RV. Periodontal conditions in subjects following orthodontic therapy. A preliminary study. Eur J Orthod. 2007;29:477-81. https://doi.org/10.1093/ejo/cjm050.

5. Sadowsky C, BeGole EA. Long-term effects of orthodontic treatment on periodontal health. Am J Orthod. 1981;80:156-72. https://doi. org/10.1016/0002-9416(81)90216-5.

6. Alstad S, Zachrisson BU. Longitudinal study of periodontal condition associated with orthodontic treatment in adolescents. Am J Orthod. 1979;76:277-86. https://doi.org/10.1016/0002-9416(79)90024-1.

7. Pellegrini P, Sauerwein R, Finlayson T, McLeod J, Covell DA, Maier T, et al. Plaque retention by self-ligating vs elastomeric orthodontic brackets: quantitative comparison of oral bacteria and detection with adenosine triphosphate-driven bioluminescence. Am J Orthod Dentofac Orthop. 2009;135(426):e1-9. https://doi.org/10.1016/j.ajodo.2008.12.002 discussion 426-427.

8. Chapple ILC, Mealey BL, Van Dyke TE, Bartold PM, Dommisch H, Eickholz $P$, et al. Periodontal health and gingival diseases and conditions on an intact and a reduced periodontium: consensus report of workgroup 1 of the 2017 World workshop on the classification of periodontal and periimplant diseases and conditions. J Periodontol. 2018;89(Suppl 1):74-84. https://doi.org/10.1002/JPER.17-0719.

9. Kouraki E, Bissada NF, Palomo JM, Ficara AJ. Gingival enlargement and resolution during and after orthodontic treatment. NY State Dent J. 2005;71:34-7

10. Zachrisson S, Zachrisson BU. Gingival condition associated with orthodontic treatment. Angle Orthod 1972;42:26-34. https://doi. org/10.1043/0003-3219(1972)042<0026:GCAWOT>2.0.CO;2.

11. Trossello VK, Gianelly AA. Orthodontic treatment and periodontal status. J Periodontol. 1979;50:665-71. https://doi.org/10.1902/jop.1979.50.12.665.

12. Trackman PC, Kantarci A. Connective tissue metabolism and gingival overgrowth. Crit Rev Oral Biol Med. 2004;15:165-75.

13. Ristic M, Vlahovic Svabic M, Sasic M, Zelic O. Effects of fixed orthodontic appliances on subgingival microflora. Int J Dent Hyg. 2008;6:129-36. https://doi.org/10.1111/j.1601-5037.2008.00283.x.

14. Tapia CV, Batarce C, Amaro J, Hermosilla G, Rodas PI, Magne F. Microbiological characterisation of the colonisation by Candida sp in patients with orthodontic fixed appliances and evaluation of host responses in saliva. Mycoses. 2019;62:247-51. https://doi.org/10.1111/myc.12880.

15. Manuelli M, Marcolina M, Nardi N, Bertossi D, De Santis D, Ricciardi G, et al. Oral mucosal complications in orthodontic treatment. Minerva Stomatol. 2019;68:84-8. https://doi.org/10.23736/S0026-4970.18.04127-4.

16. Kasmaei P, Amin Shokravi F, Hidarnia A, Hajizadeh E, Atrkar-Roushan Z, Karimzadeh Shirazi K, et al. Brushing behavior among young adolescents: does perceived severity matter. BMC Public Health. 2014;14:8. https://doi. org/10.1186/1471-2458-14-8.

17. Antoniazzi RP, Miranda LA, Zanatta FB, Islabão AG, Gustafsson A, Chiapinotto GA, et al. Periodontal conditions of individuals with Sjögren's 
syndrome. J Periodontol. 2009;80:429-35. https://doi.org/10.1902/ jop.2009.080350.

18. Trombelli L, Farina R. A review of factors influencing the incidence and severity of plaque-induced gingivitis. Minerva Stomatol. 2013;62:207-34.

19. Reali L, Zuliani E, Gabutti L, Schönholzer C, Marone C. Poor oral hygiene enhances gingival overgrowth caused by calcineurin inhibitors. J Clin Pharm Ther. 2009;34:255-60. https://doi.org/10.111 1/j.1365-2710.2008.01000.x.

20. Somacarrera ML, Lucas M, Scully C, Barrios C. Effectiveness of periodontal treatments on cyclosporine-induced gingival overgrowth in transplant patients. Br Dent J. 1997;183:89-94.

21. Zanatta FB, Ardenghi TM, Antoniazzi RP, Pinto TMP, Rösing CK. Association between gingivitis and anterior gingival enlargement in subjects undergoing fixed orthodontic treatment. Dental Press J Orthod. 2014;19:59-66. https://doi.org/10.1590/2176-9451.19.3.059-066.oar.

22. Zanatta FB, Ardenghi TM, Antoniazzi RP, Pinto TMP, Rösing CK. Association between gingival bleeding and gingival enlargement and oral healthrelated quality of life (OHRQoL) of subjects under fixed orthodontic treatment: a cross-sectional study. BMC Oral Health. 2012;12:53. https:// doi.org/10.1186/1472-6831-12-53

23. Seymour RA, Smith DG, Turnbull DN. The effects of phenytoin and sodium valproate on the periodontal health of adult epileptic patients. J Clin Periodontol. 1985;12:413-9. https://doi.org/10.1111/j.1600051X.1985.tb01377.x.

24. Sibaud V, Vigarios E, Tavitian S, Cougoul P, de Bataille C, Campana F, et al. Accroissements gingivaux: approche pragmatique. Annales de dermatologie et de vénéréologie. 2016;143:467-81.

25. Silness J, Loe H. Periodontal disease in pregnancy. II. Correlation between oral hygiene and periodontal condition. Acta Odontol Scand. 1964;22:121-35.

26. Löe H. The Gingival Index, the Plaque Index and the Retention Index systems. J Periodontol. 1967;38:610-6. https://doi.org/10.1902/ jop.1967.38.6.610.

27. De Rouck T, Eghbali R, Collys K, De Bruyn H, Cosyn J. The gingival biotype revisited: transparency of the periodontal probe through the gingival margin as a method to discriminate thin from thick gingiva. J Clin Periodontol. 2009;36:428-33. https://doi.org/10.1111/j.1600-051X.2009.01398 $x$

28. Pacheco MCT, Casagrande CF, Teixeira LP, Finck NS, de Araújo MTM. Guidelines proposal for clinical recognition of mouth breathing children. Dental Press J Orthod. 2015;20:39-44. https://doi.org/10.1590/21769451.20.4.039-044.oar.

29. Albino JE, Lawrence SD, Lopes CE, Nash LB, Tedesco LA. Cooperation of adolescents in orthodontic treatment. J Behav Med. 1991;14:53-70

30. Studen-Pavlovich D, Ranalli DN. Periodontal and soft tissue prevention strategies for the adolescent dental patient. Dent Clin North Am. 2006;50:51-67. https://doi.org/10.1016/j.cden.2005.11.001.

31. Erbe C, Klees V, Braunbeck F, Ferrari-Peron P, Ccahuana-Vasquez RA, Timm $\mathrm{H}$, et al. Comparative assessment of plaque removal and motivation between a manual toothbrush and an interactive power toothbrush in adolescents with fixed orthodontic appliances: a single-center, examinerblind randomized controlled trial. Am J Orthod Dentofac Orthop. 2019;155:462-72. https://doi.org/10.1016/j.ajodo.2018.12.013.

32. Atassi F, Awartani F. Oral hygiene status among orthodontic patients. J Contemp Dent Pract. 2010;11:E025-32.
33. Arab S, Nouhzadeh Malekshah S, Abouei Mehrizi E, Ebrahimi Khanghah A, Naseh R, Imani MM. Effect of fixed orthodontic treatment on salivary flow, pH and microbial count. J Dent (Tehran). 2016;13:18-22.

34. Christersson CE, Dunford RG, Glantz PO, Baier RE. Effect of critical surface tension on retention of oral microorganisms. Scand J Dent Res. 1989;97:247-56. https://doi.org/10.1111/j.1600-0722.1989.tb01609.x.

35. Gibbons RJ. Bacterial adhesion to oral tissues: a model for infectious diseases. J Dent Res. 1989;68:750-60. https://doi.org/10.1177/0022034589 0680050101.

36. Ulukapi H, Koray F, Efes B. Monitoring the caries risk of orthodontic patients. Quintessence Int. 1997:28:27-9.

37. Eliades T, Viazis AD, Eliades G. Bonding of ceramic brackets to enamel: morphologic and structural considerations. Am J Orthod Dentofac Orthop. 1991;99:369-75. https://doi.org/10.1016/0889-5406(91)70020-W.

38. Eliades T, Viazis AD, Lekka M. Failure mode analysis of ceramic brackets bonded to enamel. Am J Orthod Dentofac Orthop. 1993;104:21-6. https ://doi.org/10.1016/S0889-5406(08)80120-5.

39. Forsberg CM, Brattström V, Malmberg E, Nord CE. Ligature wires and elastomeric rings: two methods of ligation, and their association with microbial colonization of Streptococcus mutans and lactobacilli. Eur J Orthod. 1991;13:416-20. https://doi.org/10.1093/ejo/13.5.416.

40. Türkkahraman H, Sayin MO, Bozkurt FY, Yetkin Z, Kaya S, Onal S. Archwire ligation techniques, microbial colonization, and periodontal status in orthodontically treated patients. Angle Orthod 2005;75:231-6. https:// doi.org/10.1043/0003-3219(2005)075<0227:ALTMCA>2.0.CO;2.

41. SukontapatiparkW, el-Agroudi MA, Selliseth NJ, Thunold K, Selvig KA. Bacterial colonization associated with fixed orthodontic appliances. A scanning electron microscopy study. Eur J Orthod. 2001;23:475-84. https //doi.org/10.1093/ejo/23.5.475

42. Mehta P, Lim LP. The width of the attached gingiva-much ado about nothing? J Dent. 2010;38:517-25. https://doi.org/10.1016/j.jdent 2010.04.007.

43. Wennström JL. Lack of association between width of attached gingiva and development of soft tissue recession. A 5-year longitudinal study. J Clin Periodontol. 1987;14:181-4.

44. Agudio G, Cortellini P, Buti J, Pini Prato G. Periodontal conditions of sites treated with gingival augmentation surgery compared with untreated contralateral homologous sites: an 18- to 35-year long-term study. J Periodontol. 2016;87:1371-8. https://doi.org/10.1902/jop.2016.160284.

45. Trombelli L, Scapoli C, Tatakis DN, Grassi L. Modulation of clinical expression of plaque-induced gingivitis: effects of personality traits, social support and stress. J Clin Periodontol. 2005;32:1143-50. https://doi. org/10.1111/j.1600-051X.2005.00835.X.

46. Lee SM, Yoo SY, Kim H-S, Kim K-W, Yoon Y-J, Lim S-H, et al. Prevalence of putative periodontopathogens in subgingival dental plaques from gingivitis lesions in Korean orthodontic patients. J Microbiol. 2005;43:260-5.

47. Lo BAM, Di Marco R, Milazzo I, Nicolosi D, Cali G, Rossetti B, et al. Microbiological and clinical periodontal effects of fixed orthodontic appliances in pediatric patients. New Microbiol. 2008;31:299-302.

\section{Publisher's note}

Springer Nature remains neutral with regard to jurisdictional claims in published maps and institutional affiliations.

Ready to submit your research? Choose BMC and benefit from:

- fast, convenient online submission

- thorough peer review by experienced researchers in your field

- rapid publication on acceptance

- support for research data, including large and complex data types

- gold Open Access which fosters wider collaboration and increased citations

- maximum visibility for your research: over 100M website views per year

At BMC, research is always in progress.

Learn more biomedcentral.com/submissions 